influence on its volume. For, from the physico-chemical point of view the vitreous body belongs to the hydrophil emulsoids and it is known that the degree of swelling of such emulsoids is dependent, among other factors, chiefly on the acid-base equilibrium and that, within certain limits, the lower the hydrogen ion concentration the greater is the swelling. It would seem, therefore, that in the observed increased alkalinity of the vitreous body lies a possible explanation of the increased intraocular tension in glaucoma.

One of the difficulties of the currently accepted explanation of primary glaucoma, as due to diminished outflow through the canal of Schlemm, is that the anterior chamber is not deeper as would be expected but is actually shallower than normal. On the present view, however, a shallow anterior chamber would follow as a natural result from the presence of a swollen vitreous, the swelling being due to an alteration of its acid-base equilibrium, not, however, in the direction of increased acidity as put forward by Fischer, but in the direction of increased alkalinity.

As regards the cause of the disturbance no explanation can be offered at present but it is suggested that more attention should be paid to the blood in glaucoma.

\title{
REFERENCES
}

1. Fischer.-Pflüger's. Arch. f. Physiol., Vol. CXXVII, pp. 1-3, 1909.

2. Meesmann.-Arch. f. Augenheilk., Vol. XCIV, p. 115, 1924.

3. Michaelis u. Gyemann.-Biochem. Zeitschr., Vol. CIX, p. 165, 1920.

4. Hertel.-Arch.f. Ophthal., Vol. CV, p. 421, 1921.

\section{CHANGES IN REFRACTION ASSOCIATED WITH TRANSIENT GLYCOSURIA}

BY

\section{A. J. Ballantyne \\ GLASGOW}

As an addendum to the important paper of Dr. W. Stewart DukeElder in the April number of the British Journal of Ophthalsologiy, the following case may be of interest.

Mr. D.F.C., aged 58 years, a business man of heavy build, came under my care in March, 1923, owing to a defect in the vision of his left eye which his optician was unable to correct with glasses. He had been aware of a defect in this eye for twenty years. Vision (March, 1923) was R. $=5 / 9, \mathrm{~L} .=5 / 12$, and with correction, $5 / 5$ and $5 / 6$. He gave a "gouty" history, and his eyelids presented several chalazia and conjunctival lithiases. On ophthalmoscopic examination the right eye was found to be normal except for the 
presence of a small patch of opaque nerve fibres at the upper nasal border of the disc. The left eye showed an irregularly circular opacity in the central part of the posterior cortex of the lens, and there was a large area of opaque nerve fibres completely surrounding the disc.

In October, 1923, his correcting glasses were :

$$
\begin{aligned}
& \text { R. + 0.75D.s. }=+1.5 \mathrm{D} \text {. cyl. axis } 45^{\circ} \\
& \text { L. }-0.25 \mathrm{D} . \mathrm{s} . \leftrightharpoons+1.5 \mathrm{D} \text {. cyl. axis } 150^{\circ}
\end{aligned}
$$

and with these R.V. was $5 / 5$ and L.V. 5/12.

In April, 1924, he complained of a spot before the right eye, and one could now detect a very small spot of opacity in the centre of the posterior cortex of the right lens and one sub-capsular vacuole in the centre of the anterior cortex. The opacities in the left eye were more extensive. Corrected vision was still $\bar{j} / \ddot{j}$ in the right eye and in the left had fallen to $5 / 18$.

Early in December, 1924, he, became alarmed on account of a considerable falling off in the vision of the right eye, which uncorrected was now 5/24. Retinoscopy showed that the refraction of the right eye had changed in the direction of increased hypermetropia, and with +1.75 D.s. $\leftrightharpoons+1.5 \mathrm{D}$. cyl. axis $45^{\circ}$ vision could be again brought up to $5 / 5$. This correction was ordered but he was asked to retain his old glasses as the change might be temporary. Ophthalmoscopically, the only change was that the lens opacity in the right eye had extended slightly downwards so that it was now a delicate streak rather than a small spot.

On inquiry I found that, on the advice of some friends, he had been drinking large quantities of soda-water with the object of reducing his weight. The result was a reduction of more than a stone in his weight within a few weeks. At the same time he felt ill and suffered from bronchitis and gastric catarrh. Dr. James Stewart, Crosshill, whom he consulted at the beginning of November, 1924, found a considerable reaction for sugar in the urine, and the blood sugar, by McLean's test, amounted to 0.212. The glycosuria, however, disappeared with a slight modification in diet and was not observed again.

Early in January, 1925, he again complained of failing vision, and the right eye had now become less hypermetropic. With $+1.25 \mathrm{D} . \mathrm{s}$. $こ+1.25 \mathrm{D}$. cyl. axis $45^{\circ}$ vision was $5 / 5$. One month later the correcting glass was $+0.75 \mathrm{D} . \mathrm{s}$. $\subsetneq+1.5 \mathrm{D}$. cyl. axis $45^{\circ}$; that is to say, the refraction had returned to the value found in October, 1923, and the vision of this eye was still $5 / 5$.

The rather sudden increase and diminution of the hypermetropia of the right eye was not accompanied by corresponding changes in the visible structure of the lens. In the left eye, from the date of his first observation, there had been progressive increase in the density of the opacity, and vision, with correction, had fallen 
progressively from 5/6 in March, 1923, to "fingers" in February, 1925. No change in the refraction of this eye could be made out.

He was treated at first with local applications of potassium iodide and dionin, and latterly with the Blache ointment of calcium and iodine, but without any apparent modification of the progress of the condition.

\section{HELMHOLTZ'S THEORY OF ACCOMMODATION}

BY

\section{H. HARTRIDGE}

KING'S COLLEGE, CAMBRIDGE

Ir is an interesting fact that the three theories which are particularly associated with the name of Helmholtz have all been receiving support as the result of recent experimental work. The trichromatic theory of colour vision, the resonance theory of hearing, and the spherical theory of accommodation one and all fell from popular favour on Helmholtz's death. The attacks of Edridge Green on the trichromatic theory, of Thomas Wrightson on the resonance theory, and of Tscherning on the spherical theory produced effects of undeniable magnitude. Now, however, these attacks have been stayed and the three theories are returning to their orginal popularity.

The history of Helmholtz's theory of accommodation may be briefly stated as follows : As is well known the physical basis of the theory requires that the crystalline lens on accommodation for near objects should become both thicker and smaller in diameter. It is a deduction from the theory that the lens, when removed from the eyeball should be in the fully accommodated state. Tscherning at first questioned every one of these statements, and, in the diagram published in his physiological optics, he showed neither a change in diameter nor in thickness. Many other ophthalmologists repeated Helmholtz's measurements and confirmed them in practically every detail. As a result Tscherning modified his position so that he showed in his diagram exhibited at the Thomas Young Oration, delivered to the Optical Society in 190\%, a change in both diameter and thickness. He still held, however, to his original contention that the lens, when removed from the eyeball should be adjusted for distant vision and not fully accommodated as Helmholtz supposed.

Of recent work on this subject a paper by Fincham (Trans. Optical Soc., Vol. XXVI, No. 5, 1924-5) is of great interest. This author, after reviewing the two rival theories in some 